Article

\title{
Enhanced Acetone Sensing Characteristics of ZnO/Graphene Composites
}

\author{
Hao Zhang ${ }^{1,2}$, Yuan Cen ${ }^{3}$, Yu Du ${ }^{3, *}$ and Shuangchen Ruan ${ }^{1, *}$ \\ 1 Shenzhen Key Laboratory of Laser Engineering, College of Optoelectronic Engineering, \\ Shenzhen University, Shenzhen 518060, China; haozhang@szu.edu.cn \\ 2 Key Laboratory of Optoelectronic Devices and Systems of Ministry of Education and Guangdong Province, \\ College of Optoelectronic Engineering, Shenzhen University, Shenzhen 518060, China \\ 3 Shenzhen Key Laboratory of Sensor Technology, College of Physics Science and Technology, \\ Shenzhen University, Shenzhen 518060, China; cenyuan900927@163.com \\ * Correspondence: duyu@szu.edu.cn (Y.D.); scruan@szu.edu.cn (S.R.); Tel.: +86-755-2653-8886 (Y.D.)
}

Academic Editors: Eduard Llobet and Stella Vallejos

Received: 21 September 2016; Accepted: 3 November 2016; Published: 9 November 2016

\begin{abstract}
ZnO} /$ graphene $(\mathrm{ZnO}-\mathrm{G})$ hybrid composites are prepared via hydrothermal synthesis with graphite, $\mathrm{N}$-methyl-pyrrolidone (NMP), and $\mathrm{Zn}\left(\mathrm{NO}_{3}\right)_{2} \cdot 6 \mathrm{H}_{2} \mathrm{O}$ as the precursors. The characterizations, including X-ray diffraction (XRD), thermogravimetric analyses (TGA), Raman spectroscopy, and transmission electron microscopy (TEM) indicate the formation of ZnO-G. Gas sensors were fabricated with $\mathrm{ZnO}-\mathrm{G}$ composites and $\mathrm{ZnO}$ as sensing material, indicating that the response of the $\mathrm{ZnO}$ towards acetone was significantly enhanced by graphene doping. It was found that the $\mathrm{ZnO}-\mathrm{G}$ sensor exhibits remarkably enhanced response of 13.3 at the optimal operating temperature of $280{ }^{\circ} \mathrm{C}$ to $100 \mathrm{ppm}$ acetone, an improvement from 7.7 with pure $\mathrm{ZnO}$.
\end{abstract}

Keywords: graphene; acetone sensing; $\mathrm{ZnO}$

\section{Introduction}

Chemical sensors play an important role in the areas of emissions control, environmental protection, public safety, and human health [1]. It is well known that high sensitivity, fast response and recovery, and selective detection are required for real-time monitoring of harmful gases and preventing possible disasters due to toxic gas [2-4]. Among them, the detection of acetone vapor is very important in daily life. Medical investigations have shown that the acetone concentration in exhaled breath from a healthy human body is lower than $0.8 \mathrm{ppm}$, while that for a diabetic patient is higher than 1.8 ppm [5-7]. As an important chemical material, acetone vapor should be monitored, and kinds of metal oxides have been applied. Zinc Oxide-as an n-type semiconductor material-has been widely investigated as a field-effect transistor [7], optical device [8], dye-sensitized solar cell [9], and solid-state gas sensor [10,11]. Recently, ZnO-based sensors have been investigated for the detection of acetone vapor at various concentration levels [12-15].

Graphene, known as "the thinnest material in our universe", with only one-atom thickness, has attracted huge attention since its discovery. Because of its unique features of high surface area, light weight, high electron mobility, and mechanical strength, graphene can make a highly promising platform for gas detection. In order to improve the sensing performances of graphene-based sensors, various sensitive materials have been selected to modify the graphene conductive network, and they play important roles in improving the sensitivity and selectivity of resultant gas sensors [16-19]. To date, the most popular method of preparing monolayer or multilayer graphene is the micromechanical cleavage or chemical exfoliation of highly oriented pyrolytic graphite or graphite oxide [20-25]. Recently, exfoliated graphene was prepared directly from graphite with solvothermal method, offering 
another method for graphene preparation [26]. Meanwhile, to the best of our knowledge, the enhanced acetone sensing performance of the $\mathrm{ZnO}$ /graphene $(\mathrm{ZnO}-\mathrm{G})$ composites prepared by this method has yet to be reported.

Hence, we present a simple and economically attractive route for the synthesis of the $\mathrm{ZnO}-\mathrm{G}$ composites via a facile hydrothermal method on a large scale. Simultaneously, to improve the acetone sensing performance, the graphene was exfoliated directly from graphite by solvothermal treatment. Improved gas sensitivity and selectivity of $\mathrm{ZnO}-\mathrm{G}$ towards acetone was achieved. The effects of graphene doping on the response and response-recovery time at different operating temperatures and gas concentration towards acetone were also investigated.

\section{Materials and Methods}

\subsection{Chemicals}

All chemicals were of analytical grade and were used as received without further purification. Graphite and N-methyl-pyrrolidone (NMP) and $\mathrm{Zn}\left(\mathrm{NO}_{3}\right)_{2} \cdot 6 \mathrm{H}_{2} \mathrm{O}$, were supplied by Beijing Chemical Corp, Ltd. (Beijing, China). The water used throughout all experiments was purified through a Millipore system.

\subsection{Exfoliation of Graphene}

The exfoliation of Graphene has been proposed [27]. In a typical synthesis, $0.5 \mathrm{~g}$ of graphite was dispersed in $35 \mathrm{~mL}$ of NMP solvent, which was then sealed into a $40 \mathrm{~mL}$ Teflon-lined autoclave and solvothermally treated at $200{ }^{\circ} \mathrm{C}$ for 3 days. The autoclave was cooled naturally, and the as-obtained sample was sonicated for $1 \mathrm{~h}$ in a sonication bath. After the removal of macroscopic aggregates and a thick layer of graphene by centrifugation (5-7 krpm for 7-10 $\mathrm{min}$ ), a dark suspension was obtained. After a few minutes, a graphene film was formed at the interface.

\subsection{Preparation of $\mathrm{ZnO} \mathrm{O} G$ Composites}

$\mathrm{ZnO}-\mathrm{G}$ composite was prepared by in situ production of $\mathrm{ZnO}$ nanoparticles on the surface of graphene. In a typical synthesis, $2.19 \mathrm{~g} \mathrm{Zn}\left(\mathrm{NO}_{3}\right)_{2} \cdot 6 \mathrm{H}_{2} \mathrm{O}$ and $6 \mathrm{~mL}$ of graphene of NMP resolution $\left(1 \mathrm{mg} / \mathrm{mL}\right.$ ) was introduced into $20 \mathrm{~mL} \mathrm{H}_{2} \mathrm{O}$, which was sonicated for $40 \mathrm{~min}$. The aqueous dispersion was transferred into a $40 \mathrm{~mL}$ Teflon-lined stainless-steel autoclave and heated at $180{ }^{\circ} \mathrm{C}$ for $12 \mathrm{~h}$. The black product was harvested by centrifugation and washed with water and ethanol several times, and dried at $60{ }^{\circ} \mathrm{C}$ for several hours. For comparison, the pure $\mathrm{ZnO}$ was prepared by a similar method without the addition of graphene.

\subsection{Characterizations}

Powder X-ray diffraction (XRD) data were recorded on a Rigaku D/Max-2550 diffractometer with $\mathrm{Cu}-\mathrm{K} \alpha$ radiation $(\lambda=0.15418 \mathrm{~nm})$. The transmission electron microscopic (TEM) images were taken with a JEOL JEM-3010 TEM microscope with an accelerating voltage of $200 \mathrm{kV}$. The sample for TEM characterization was prepared by placing a drop of colloidal solution on a carbon-coated copper grid and dried at room temperature. Thermogravimetric analyses (TGA) analysis was measured on ATGAQ50 instrument from $25^{\circ} \mathrm{C}$ to $800^{\circ} \mathrm{C}$. Raman spectra were obtained on Horiba-JY T64000 Raman spectromer with $514.5 \mathrm{~nm}$ wavelength incident laser light.

\subsection{Fabrication and Gas Sensing Measurements}

The product was mixed with deionized water at a weight ratio of 4:1 to form a paste. The sensor was fabricated by coating a ceramic tube with the paste to form a $1.5 \mathrm{~mm}$ sensing film. A pair of gold electrodes was installed at each end of the ceramic tube before it was coated with the paste. Each electrode was connected with two Pt wires. A Ni-Cr heating wire was inserted into the tube to form an indirect-heated gas sensor. Figure $1 \mathrm{a}, \mathrm{b}$ show a schematic image of the as-fabricated sensor 
and a photograph of the sensor on the socket, respectively. The Pt wires between two electrodes were almost covered by the sensing material and could not contact target gas, and thus have no effect on the sensing property. The gas sensing properties of the sensor were measured by a CGS- 8 series Intelligent Test Meter. The sensors were all heat-treated in $300{ }^{\circ} \mathrm{C}$ before gas sensing test to remove the solvent from the sensing material. The response of the sensor is defined as the ratio of sensor resistance in a target gas $\left(R_{g}\right)$ to that in dry air $\left(R_{a}\right)$ between 180 and $360{ }^{\circ} \mathrm{C}$. The time taken by the sensor to achieve $90 \%$ of the total resistance change was defined as the response time in the case of adsorption or the recovery time in the case of desorption.

(a)

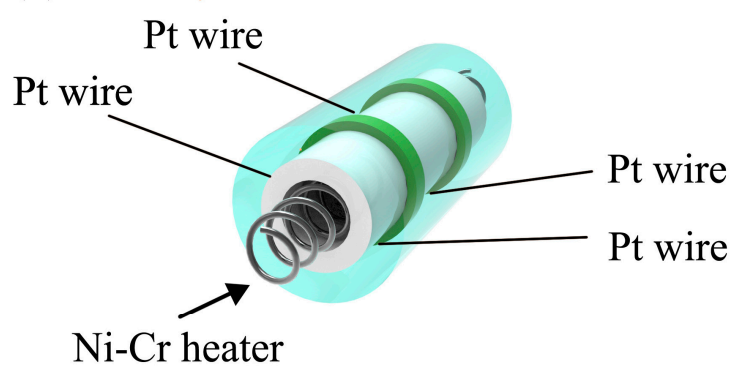

(b)

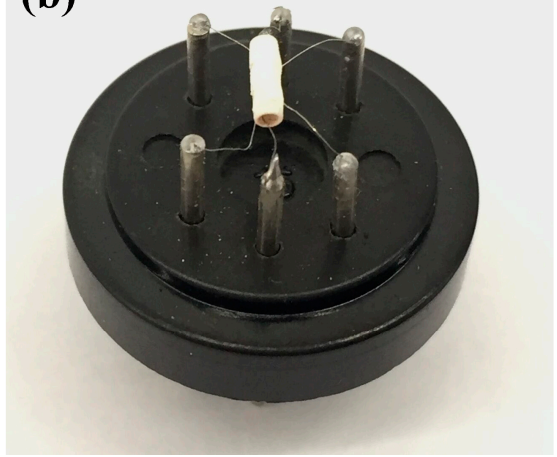

Figure 1. (a) A schematic image and (b) photograph of the $\mathrm{ZnO} /$ graphene ( $\mathrm{ZnO}-\mathrm{G})$ sensor.

\section{Results}

\subsection{Structural and Morphological Characteristics}

The powder X-ray diffraction (XRD) pattern of the as-prepared product is shown in Figure 2. All diffraction peaks can be indexed to wurtzite-structured (hexagonal) ZnO (JCPDS No. 75-0576). No impurity phases were observed from the XRD pattern, which confirms the superb purity of the product. No graphene peak was observed; this may be due to the low content of graphene in the composite materials.

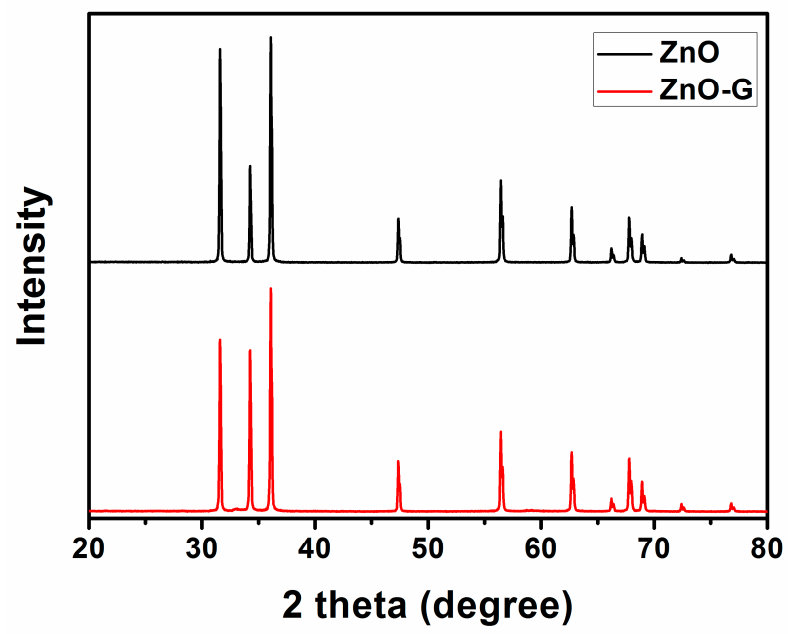

Figure 2. The powder X-ray diffraction (XRD) patterns of the products: $\mathrm{ZnO}$ (black line) and ZnO-G (red line).

Figure 3 shows the TGA curves of $\mathrm{ZnO}$ and $\mathrm{ZnO}-\mathrm{G}$ samples. The small weight loss observed in $\mathrm{ZnO}$ was $0.47 \%$, attributed to desorption of solvent molecules physically adsorbed on the materials. 
Comparably, the weight loss of $\mathrm{ZnO}-\mathrm{G}$ from room temperature to $325^{\circ} \mathrm{C}$ is attributed to the removal of surface-bound water and NMP; the decomposition of the carbon framework started from $325^{\circ} \mathrm{C}$ and continued up to $600{ }^{\circ} \mathrm{C}[28,29]$. Based on the above results, the content of $\mathrm{ZnO}$ in $\mathrm{ZnO}-\mathrm{G}$ hybrids is about $96.4 \%$.

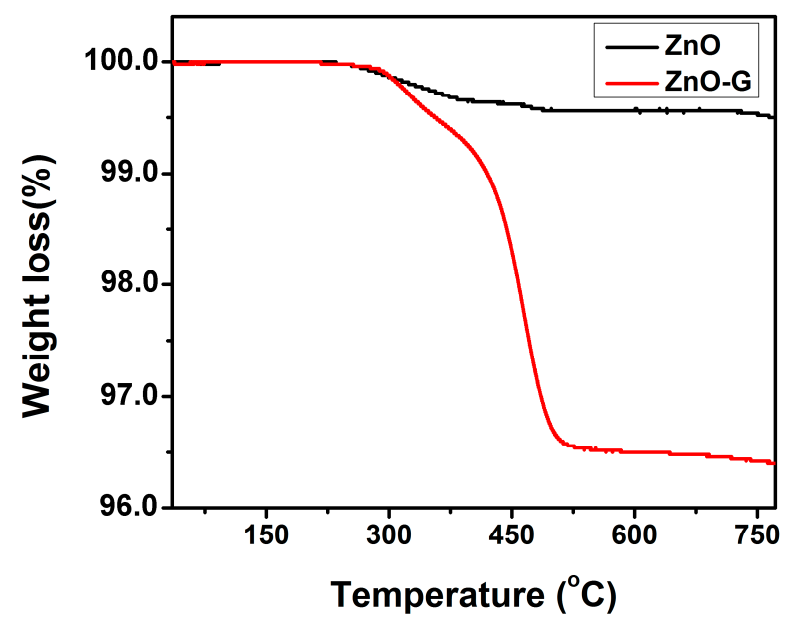

Figure 3. Thermogravimetric analysis (TGA) of $\mathrm{ZnO}$ and $\mathrm{ZnO}-\mathrm{G}$ samples.

Figure 4 shows the Raman spectra of graphene and pristine graphite. The two strong peaks of the D peak $\left(\sim 1351 \mathrm{~cm}^{-1}\right)$ and $\mathrm{G}$ peak $\left(\sim 1595 \mathrm{~cm}^{-1}\right)$ were observed, corresponding to the diamondoid and graphitic graphene structures, respectively. The obtained D peak of graphene is higher than that of graphite, which indicates that the graphene that separated from the solvent may have more defects than graphite. This can be explained as below: although graphene was directly exfoliated from graphite, it will have some defects after exfoliation. However, the $2 \mathrm{D}$ lines $\left(\sim 2700 \mathrm{~cm}^{-1}\right)$ of the two samples are nearly the same, which illustrates that the graphene that is collected has a majority of layered graphene [30].

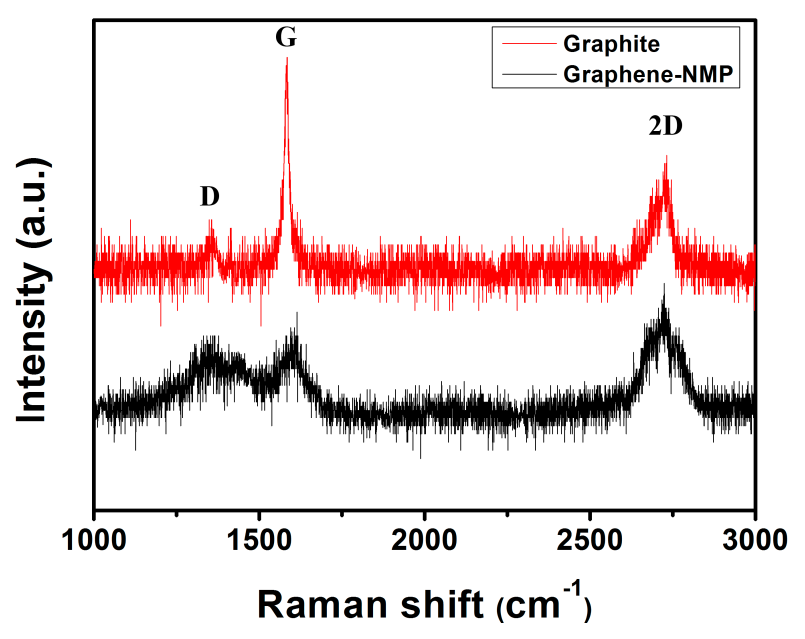

Figure 4. Raman spectra of graphite and graphene.

To observe the dispersions in NMP, TEM is employed by placing drops of the dispersions on microgrids. Figure 5a shows TEM images of representative graphene prepared by solvothermal treatment. Some flakes tend to crinkle or roll because of stress from the edges, and are similar to those prepared without solvothermal treatment. A TEM image of ZnO-G (Figure 5b) exhibits a typical morphology similar to graphene-based materials. Graphene with the size of about 3-4 $\mu \mathrm{m}$ 
is seen, and a few hexagonal $\mathrm{ZnO}$ nanoparticles with size $200-300 \mathrm{~nm}$ are decorated on the surface of graphene, indicating the formation of $\mathrm{ZnO}-\mathrm{G}$ hybrids. This reveals that hydrothermal treatment of exfoliated graphene and $\mathrm{Zn}\left(\mathrm{NO}_{3}\right)_{2} \cdot 6 \mathrm{H}_{2} \mathrm{O}$ solution is an effective method for the preparation of ZnO-G nanocomposite.

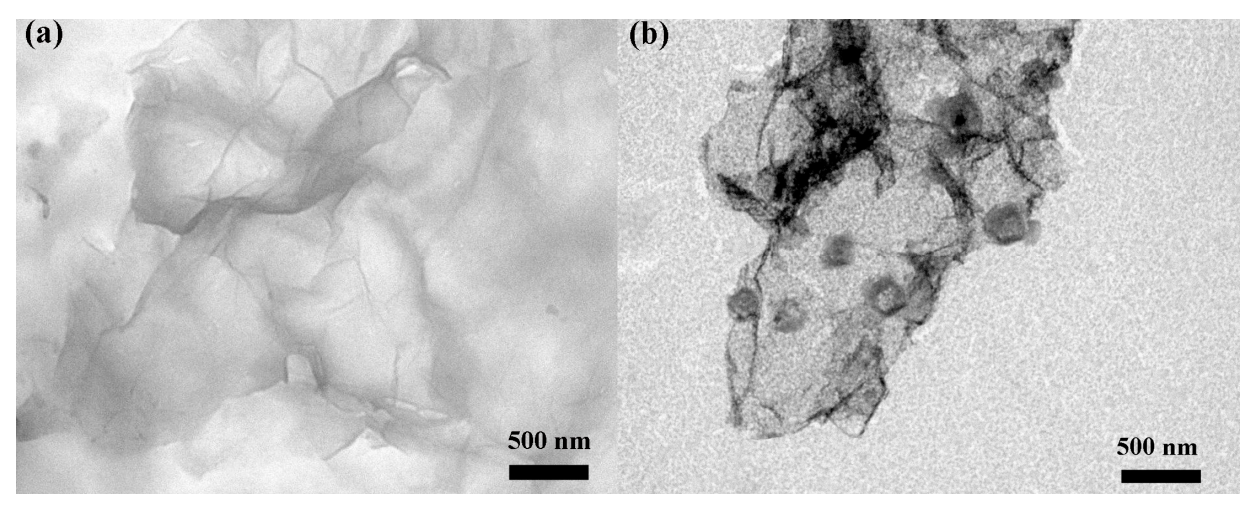

Figure 5. Transmission electron microscopy (TEM) images of (a) exfoliated graphene and (b) ZnO-G.

\subsection{Acetone Sensing Properties}

The responses of the sensors using pure $\mathrm{ZnO}$ and $\mathrm{ZnO}-\mathrm{G}$ to $100 \mathrm{ppm}$ acetone were measured at various temperatures in order to find the optimum operating temperature. As shown in Figure 6, the maximum response of the sensor based on pure $\mathrm{ZnO}$ was at $300{ }^{\circ} \mathrm{C}$. Comparatively, the sensitivity of the $\mathrm{ZnO}-\mathrm{G}$ sensor reached 13.3 at $280^{\circ} \mathrm{C}$. The response increases with increasing operating temperature up to $280^{\circ} \mathrm{C}$, since sufficient thermal energy is essential to overcome the activation energy barrier of chemisorption and surface reaction. Beyond $280^{\circ} \mathrm{C}$, the sensor sensitivity decreases, which may be due to the fact that the amount of adsorbed gas on the surface of the material has decreased, while the desorption process becomes dominant with increasing operating temperature, leading to a reduction in sensitivity. When the desorption rate of the gas becomes equal to that of adsorption, the maximum loading of chemisorbed ions is reached at the optimum temperature, accelerating the oxidation of acetone molecules and resulting in the highest sensitivity [31]. ZnO-G sensor exhibits relatively higher sensitivity and lower optimum sensing temperature than that of pure $\mathrm{ZnO}$.

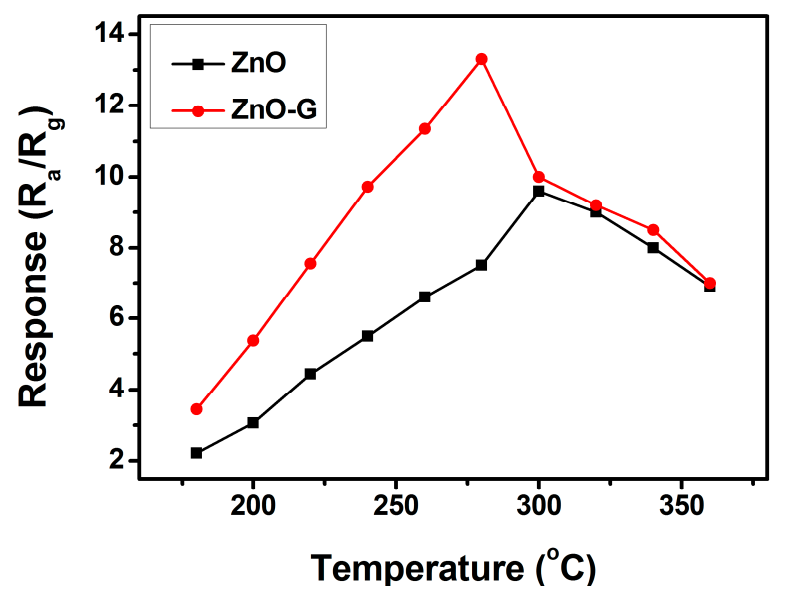

Figure 6. Response versus operating temperature of $\mathrm{ZnO}$ and $\mathrm{ZnO}-\mathrm{G}$ sensors exposed to $100 \mathrm{ppm}$ of acetone.

Figure 7 shows the response of the sensors based on $\mathrm{ZnO}$ and $\mathrm{ZnO}-\mathrm{G}$ to acetone in the range of $10-10,000 \mathrm{ppm}$ at $280^{\circ} \mathrm{C}$. The response of both sensors to acetone increases rapidly with the increasing 
of gas concentration below 5000 ppm, and increases slowly above 10,000 ppm. This indicates that its adsorption tends to saturation, and the upper concentration limit for acetone detection is $5000 \mathrm{ppm}$. Notably, the $\mathrm{ZnO}-\mathrm{G}$ shows higher sensitivity to acetone in the entire range of detected concentration compared to $\mathrm{ZnO}$, which indicates that the sensor is very suitable for the detection of acetone in a wide range of concentrations. This unsaturation phenomenon to relatively high acetone concentration $(<5000 \mathrm{ppm})$ may result from the high surface area of $\mathrm{ZnO}-\mathrm{G}$, providing abundant surface active sites and absorbing a large amount of target gas molecules.

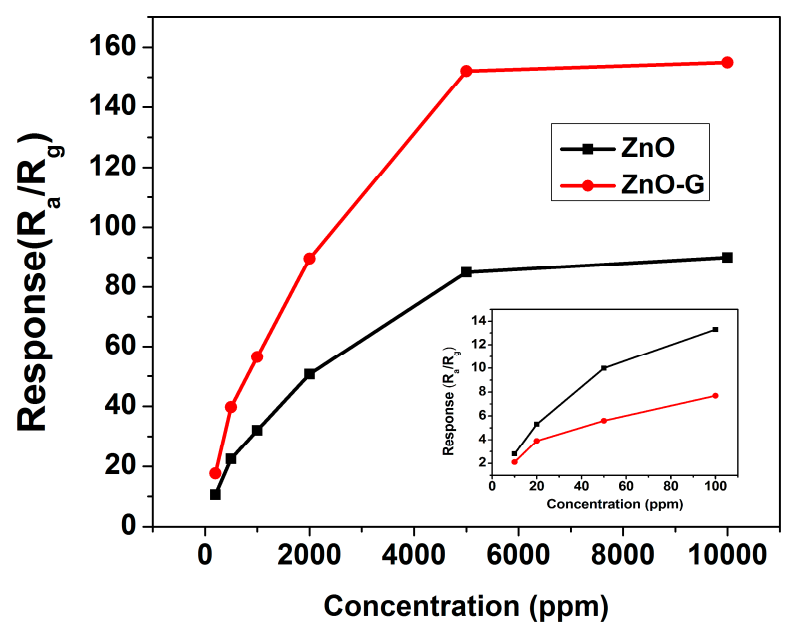

Figure 7. The responses of $\mathrm{ZnO}$ and $\mathrm{ZnO}-\mathrm{G}$ sensors to different concentrations of acetone. The inset: the responses to acetone in the range of $10-100 \mathrm{ppm}$ at $280^{\circ} \mathrm{C}$.

It is well known that the response and recovery characteristics are important for evaluating the performance of gas sensors. To investigate the response and recovery behaviors of $\mathrm{ZnO}$ and $\mathrm{ZnO}-\mathrm{G}$, the sensor was sequentially exposed to $10,20,50$ and $100 \mathrm{ppm}$ acetone at $280{ }^{\circ} \mathrm{C}$. As seen in Figure 8 , compared to $\mathrm{ZnO}, \mathrm{ZnO}-\mathrm{G}$ exhibits faster response and recovery behaviors to acetone. The response of $\mathrm{ZnO}-\mathrm{G}$ is about 2.80, 5.20, 9.79 and 13.30, while that of $\mathrm{ZnO}$ is 1.40, 3.90, 5.65 and 7.72 to 10, 20, 50 and 100 ppm acetone, respectively (Figure 8a). To compare the response and recovery behaviors of $\mathrm{ZnO}$ and $\mathrm{ZnO}-\mathrm{G}$, an enlarged image of the gas sensing process to $10 \mathrm{ppm}$ acetone is shown (Figure $8 \mathrm{~b}$ ). The response and recovery times of $\mathrm{ZnO}-\mathrm{G}$ are about 1 and $2 \mathrm{~s}$, and are $16 \mathrm{~s}$ and $22 \mathrm{~s}$ for $\mathrm{ZnO}$, indicating the faster response and recovery behaviours of $\mathrm{ZnO}$. The excellent response and recovery behavior can be explained by the high electron mobility of $\mathrm{ZnO}-\mathrm{G}$ sensors.
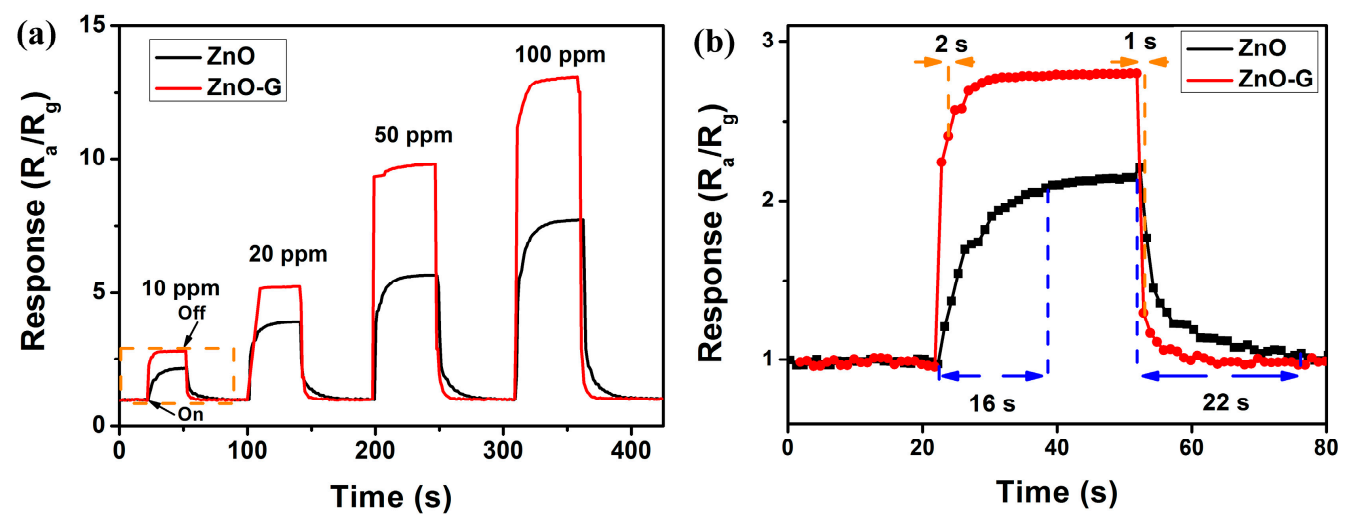

Figure 8. (a) Dynamic acetone sensing transients curve of the $\mathrm{ZnO}$ (black line) and $\mathrm{ZnO}-\mathrm{G}$ (red line) sensor to 10-100 ppm acetone gases at $280^{\circ} \mathrm{C}$; (b) An enlarged image of the selected area of Figure 8a. 
Figure 9 shows the response of $\mathrm{ZnO}$ and $\mathrm{ZnO}-\mathrm{G}$ sensors at $280{ }^{\circ} \mathrm{C}$ to $100 \mathrm{ppm}$ of various interference vapours. The responses of the $\mathrm{ZnO}$ sensor to $\mathrm{CHCl}_{3}, \mathrm{C}_{4} \mathrm{H}_{10}, \mathrm{NO}, \mathrm{H}_{2}, \mathrm{CO}$ and $\mathrm{NH}_{3}$ are 4.86, 1.25, 1.52, 1.60, 2.05 and 1.26, respectively, and for ZnO-G are 6.75, 1.08, 2.40, 1.96, 2.98 and 1.39 , indicating that graphene doping enhanced the selectivity of the $\mathrm{ZnO}-\mathrm{G}$ sensor compared to the $\mathrm{ZnO}$ sensor.

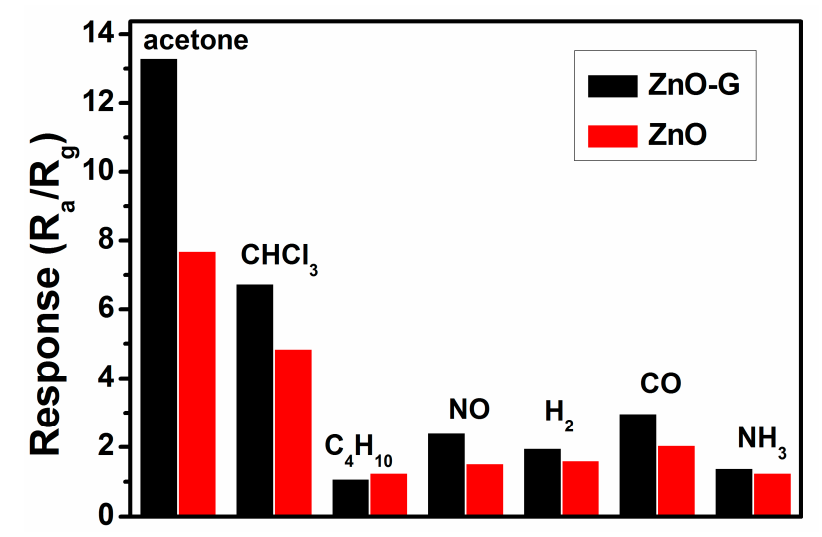

Figure 9. The response of the $\mathrm{ZnO}-\mathrm{G}$ sensor to $100 \mathrm{ppm}$ of different gases at $280{ }^{\circ} \mathrm{C}$.

Further tests for the reproducibility of the sensor based on $\mathrm{ZnO}-\mathrm{G}$ is illustrated in Figure 10. It is revealed that the sensor maintains its initial response amplitude without a clear decrease upon three successive sensing tests to 100 ppm of acetone, albeit the swift response and recovery process, indicating that the sensor has an outstanding stability throughout the cycle test.

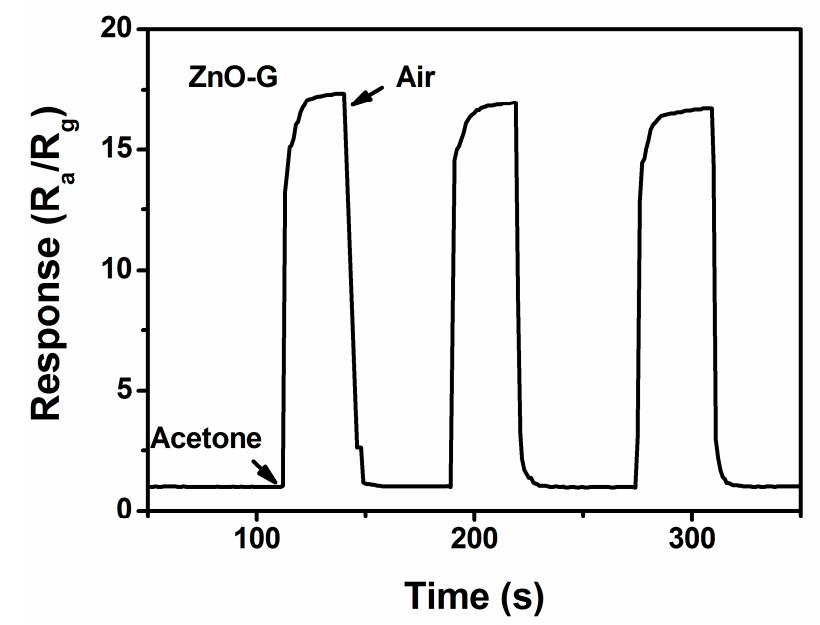

Figure 10. The reproducibility of the $\mathrm{ZnO}-\mathrm{G}$ sensor on successive exposure (three cycles) to $100 \mathrm{ppm}$ acetone at $280^{\circ} \mathrm{C}$.

\section{Discussion}

According to literature [32,33], the most probable explanation for such behavior could be as follows. The response of metal-oxide semiconductor sensors is mainly determined by the interaction of a target vapor and the surface of the metal-oxide material. The following reactions may occur in the surface reaction (Figure 11a) [34]. When acetone vapor $\left(\mathrm{CH}_{3} \mathrm{COCH}_{3}\right)$ reacts with oxygen species $\left(\mathrm{O}^{-}\right)$on the surface of a metal-oxide material, it is oxidized to carbon dioxide and water. This liberates free electrons in the $\mathrm{ZnO}$ conduction band, leading to a decrease in the resistance of an n-type semiconductor. Two reasons may account for the better performance exhibited by the $\mathrm{ZnO}-\mathrm{G}$ 
compared to pure $\mathrm{ZnO}$ sensors. Firstly, due to the high specific surface area $\left(2600 \mathrm{~m}^{2} / \mathrm{g}\right.$ [35]) of graphene, mixing graphene could increase the amount of surface active sites for the adsorption of target gas, which contribute to the improvement of sensitivity and detection of acetone in a wide range. Secondly, the introduction of $\mathrm{ZnO}-\mathrm{G}$ could improve the electron-transfer rate due to the high electron mobility of graphene and the increase in the surface area of the sensing materials due to the two-dimensional structure. With the high charge carrier mobility, graphene provides direct conduction paths for carriers to transport from the junction to the external electrode. I-V curves indicate that the incorporation of graphene films into the $\mathrm{ZnO}$ particles significantly optimizes the material's conductivity (Figure 11b). For the $\mathrm{ZnO}-\mathrm{G}$ sample, a relatively larger current (on the order of $\mu \mathrm{A}$ ) passes through the film. The calculated resistivity of the $\mathrm{ZnO}$ sample is higher than that of the $\mathrm{ZnO}-\mathrm{G}$ sample. Therefore, the electrical signals link closely and propagate rapidly, which accelerate the response and recovery process of the $\mathrm{ZnO}-\mathrm{G}$ based sensor.
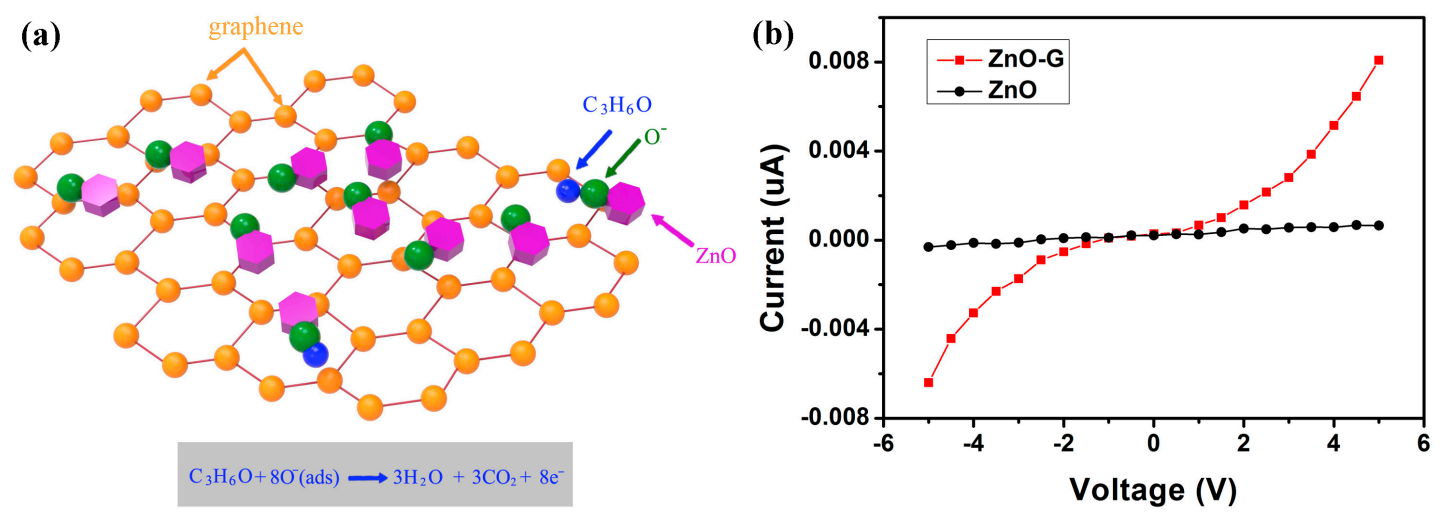

Figure 11. (a) The scheme of the proposed gas sensing mechanism: the adsorption behavior of acetone molecules on the ZnO-G nanocomposite; (b) Representative I-V curves for ZnO-G and ZnO sample.

\section{Conclusions}

This paper describes a simple liquid phase separation method for the fabrication of exfoliated graphene and a wet chemical synthesis route for $\mathrm{ZnO}-\mathrm{G}$ composites. The effects of graphene doping on the acetone sensing properties of $\mathrm{ZnO}-\mathrm{G}$ have been investigated. Evaluation of gas-sensing properties revealed that the sensor based on $\mathrm{ZnO}-\mathrm{G}$ exhibits more outstanding selectivity, higher response, and faster recovery behaviour toward acetone in contrast to those based on pure $\mathrm{ZnO}$. A response of 13.3 to $100 \mathrm{ppm}$ acetone is obtained at $280^{\circ} \mathrm{C}$. Our results indicate that graphene can significantly improve the acetone sensing properties of $\mathrm{ZnO}$, which has excellent potential applications in gas sensors.

Acknowledgments: This research work was financially supported by National Natural Science Foundation of China (Grant No. 61575129, 61275144), Guangdong Natural Science Foundation (2016A030313059), State Key Laboratory of Inorganic Synthesis and Preparative Chemistry Open Project (2015-10), Science and Technology Fund of Shenzhen (JCYJ20160307111047701) and Natural Science Foundation of SZU (82700002601).

Author Contributions: Hao Zhang proposed the idea, synthesized the materials, processed data and wrote the paper. Yuan Cen is responsible for test data. Yu Du and Shuangchen Ruan directed the research as the principal investigator (PI) of the project.

Conflicts of Interest: The authors declare no conflict of interest.

\section{References}

1. Polleux, J.; Gurlo, A.; Barsan, N.; Weimar, U.; Antonietti, M.; Niederberger, M.M. Template-Free Synthesis and Assembly of Single-Crystalline Tungsten Oxide Nanowires and their Gas-Sensing Properties. Angew. Chem. Int. Ed. 2006, 45, 267-271. [CrossRef]

2. Lee, J.H. Gas sensors using hierarchical and hollow oxide nanostructures: Overview. Sens. Actuators B 2009, 140, 319-336. [CrossRef] 
3. Pongpaiboonkul, S.; Phokharatkul, D.; Hodakc, J.H.; Wisitsoraat, A.; Hodak, S.K. Enhancement of $\mathrm{H}_{2} \mathrm{~S}$-sensing performances with $\mathrm{Fe}$-doping in $\mathrm{CaCu}_{3} \mathrm{Ti}_{4} \mathrm{O}_{12}$ thin films prepared by a sol-gel method. Sens. Actuators B 2016, 224, 118-127. [CrossRef]

4. Wang, L.L.; Lou, Z.; Fei, T.; Zhang, T. Templating synthesis of ZnO hollow nanospheres loaded with Au nanoparticles and their enhanced gas sensing properties. J. Mater. Chem. 2012, 22, 4767-4771. [CrossRef]

5. Owen, O.E.; Trapp, V.E.; Skutches, C.L.; Mozzoli, M.A.; Hoeldtke, R.D.; Boden, G.; Reichard, G.A. Acetone metabolism during diabetic ketoacidosis. Diabetes 1982, 31, 242-248. [CrossRef] [PubMed]

6. Reichard, G.A.; Skutches, C.L.; Hoeldtke, R.D.; Owen, O.E. Acetone metabolism inhumans during diabetic ketoacidosis. Diabetes 1986, 35, 668-674. [CrossRef] [PubMed]

7. Wang, X.D.; Zhou, J.; Song, J.H.; Liu, J.; Xu, N.S.; Wang, Z.L. Piezoelectric field effect transistor and nanoforce sensor based on a single ZnO nanowire. Nano Lett. 2006, 6, 2768-2772. [CrossRef] [PubMed]

8. Yang, P.D.; Yan, H.Q.; Mao, S.; Russo, R.; Johnson, J.; Saykally, R.; Morris, N.; Pham, J.; He, R.; Choietal, H.-J. Controlled growth of $\mathrm{ZnO}$ nanowires and their optical properties. Adv. Funct. Mater. 2002, 12, 323-331. [CrossRef]

9. Law, M.; Greene, L.E.; Johnson, J.C.; Saykally, R.; Yang, P.D. Nanowire dye-sensitized solar cells. Nat. Mater. 2005, 4, 455-459. [CrossRef] [PubMed]

10. Guo, W.W.; Liu, T.M.; Zeng, W.; Liu, D.J.; Chen, Y.; Wang, Z.C. Gas-sensing property improvement of ZnO by hierarchical flower-like architectures. Mater. Lett. 2011, 65, 3384-3387. [CrossRef]

11. Rai, P.; Song, H.M.; Kim, Y.S.; Song, M.K.; Oh, P.R.; Yoon, J.M.; Yu, Y.T. Microwave assisted hydrothermal synthesis of single crystalline $\mathrm{ZnO}$ nanorods for gas sensor application. Mater. Lett. 2012, 68, 90-93. [CrossRef]

12. Anno, Y.; Maekawa, Y.T.; Tamaki, J.; Asano, Y.; Hayashi, K.; Miura, N. Zinc-oxide-based semiconductor sensors for detecting acetone and caproaldehyde in the vapour of consommé soup. Sens. Actuators B 1995, 25, 623-627. [CrossRef]

13. Sahay, P.P. Zinc oxide thin film gas sensor for detection of acetone. J. Mater. Sci. 2005, 40, 4383-4385. [CrossRef]

14. Chang, S.J.; Hsueh, T.J.; Chen, I.C.; Huang, B.R. Highly sensitive ZnO nanowire CO sensors with the adsorption of Au nanoparticles. Nanotechnology 2008, 19, 175502. [CrossRef] [PubMed]

15. Zeng, Y.; Zhang, T.; Yuan, M.X.; Kang, M.H.; Lu, G.Y.; Wang, R.; Fan, H.T.; He, Y.; Yang, H.B. Growth and selective acetone detection based on ZnO nanorod arrays. Sens. Actuators B 2009, 143, 93-98. [CrossRef]

16. Xu, C.; Wang, X.; Zhu, J. Graphene-metal particle composites. J. Phys. Chem. C. 2008, 112, 19841-19845. [CrossRef]

17. Wang, L.L.; Jackman, J.A.; Ng, W.B.; Cho, N.-J. Flexible, graphene-coated biocomposite for highly sensitive, real-time molecular detection. Adv. Funct. Mater. 2016, in press.

18. Xiao, Y.; Yang, Q.Y.; Wang, Z.Y.; Zhang, R.; Gao, Y.; Sun, P.; Sun, Y.F.; Lu, G.Y. Improvement of $\mathrm{NO}_{2}$ gas sensing performance based on discoid tinoxide modified by reduced graphene oxide. Sens. Actuators B 2016, 227, 419-426. [CrossRef]

19. Ye, Z.; Tai, H.L.; Xie, T.; Yuan, Z.; Liu, C.H.; Jiang, Y.D. Room temperature formaldehyde sensor with enhanced performance based on reduced graphene oxide/titanium dioxide. Sens. Actuators B 2016, 223, 149-156. [CrossRef]

20. Wang, L.L.; Ng, W.B.; Jackman, J.A.; Cho, N.-J. Graphene gunctionalized natural microcapsules: modular building blocks for ultrahigh sensitivity bioelectronic platforms. Adv. Funct. Mater. 2016, 26, 2097-2103. [CrossRef]

21. Stankovich, S.; Piner, R.D.; Nguyen, S.T.; Ruoff, R.S. Synthesis and exfoliation of isocyanate-treated graphene oxide nanoplatelets. Carbon 2006, 44, 3342-3347. [CrossRef]

22. Paredes, J.I.; Villar-Rodil, S.; Mart_nez-Alonso, A.; Tascon, J.M.D. Graphene oxide dispersions in organic solvents. Langmuir 2008, 24, 10560-10564. [CrossRef] [PubMed]

23. Wang, S.; Chia, P.J.; Chua, L.L.; Zhao, L.H.; Png, R.Q.; Sivaramakrishnan, S.; Zhou, M.; Goh, R.G.S.; Friend, R.H.; Wee, A.T.S.; et al. Band-like transport in surface-functionalized highly solution-processable graphene nanosheets. Adv. Mater. 2008, 20, 3440-3446. [CrossRef]

24. Xu, Y.X.; Bai, H.; Lu, G.W.; Li, C.; Shi, G. Flexible graphene films via the filtration of water-soluble noncovalent functionalized graphene sheets. J. Am. Chem. Soc. 2008, 130, 5856-5867. [CrossRef] [PubMed] 
25. Lou, Z.; Chen, S.; Wang, L.L.; Jiang, K.; Shen, G.Z. An ultra-sensitive and rapid response speed graphene pressure sensors for electronic skin and health monitoring. Nano Energy 2016, 23, 7-14. [CrossRef]

26. Hernandez, Y.; Nicolosi, V.; Lotya, M.; Blighe, F.M.; Sun, Z.; De, S.; Mcgovern, I.T.; Holland, B.; Byrne, M.; Gun'ko, Y.K.; et al. High-yield production of graphene by liquid-phase exfoliation of graphite. Nat. Nanotechnol. 2008, 3, 563-568.

27. Tang, Z.H.; Zhuang, J.; Wang, X. Exfoliation of graphene from graphite and their self-assembly at the oil-water Interface. Langmuir 2010, 26, 9045-9049. [CrossRef] [PubMed]

28. Feng, Y.; Feng, N.; Wei, Y.; Zhang, G. An in situ gelatin-assisted hydrothermalsynthesis of ZnO-reduced graphene oxide composites with enhanced photo-catalytic performance under ultraviolet and visible light. RSC Adv. 2014, 4, 7933-7943. [CrossRef]

29. Gul, K.; Sohni, S.; Waqar, M.; Ahmad, F.; Nik Norulaini, N.A.; Mohd. Omar, A.K. Functionalization of magnetic chitosan with graphene oxide for removal of cationic and anionic dyes from aqueous solution. Carbohydr. Polym. 2016, 152, 520-531. [CrossRef] [PubMed]

30. Graf, D.; Molitor, F.; Ensslin, K.; Stampfer, C.; Jungen, A.; Hierold, C.; Wirtz, L. Raman imaging of graphene. Solid State Commun. 2007, 143, 44-46. [CrossRef]

31. Oh, E.; Choi, H.Y.; Jung, S.H.; Cho, S.; Kim, J.C.; Lee, K.H.; Kang, S.W.; Kim, J.; Yun, J.Y.; Jeong, S.H. High-performance $\mathrm{NO}_{2}$ gas sensor based on $\mathrm{ZnO}$ nanorod grown by ultrasonic irradiation. Sens. Actuators $B$ 2009, 141, 239-243. [CrossRef]

32. Cuong, T.V.; Pham, V.t.H.; Chung, J.S.; Shin, E.W.; Yoo, D.H.; Hahn, S.H.; Huh, J.S.; Rue, G.H.; Kim, E.J.; Hur, S.H.; Kohld, P.A. Solution-processed ZnO-chemically converted graphene gas sensor. Mater. Lett. 2010, 64, 2479-2482. [CrossRef]

33. Yi, J.; Lee, J.M.; Park, W.I. Vertically aligned ZnO nanorods and graphene hybridarchitectures for high-sensitive flexible gas sensors. Sens. Actuators B 2011, 155, 264-269. [CrossRef]

34. Song, P.; Wang, Q.; Yang, Z. Acetone sensing characteristics of ZnO hollow spheres prepared by one-pot hydrothermal reaction. Mater. Lett. 2012, 86, 168-170. [CrossRef]

35. Singh, G.; Choudhary, A.; Haranath, D.; Joshi, A.G.; Singh, N.; Singh, S.; Pasricha, R. ZnO decorated luminescent graphene as a potential gas sensor at room temperature. Carbon 2012, 50, 385-394. [CrossRef]

(C) 2016 by the authors; licensee MDPI, Basel, Switzerland. This article is an open access article distributed under the terms and conditions of the Creative Commons Attribution (CC-BY) license (http://creativecommons.org/licenses/by/4.0/). 